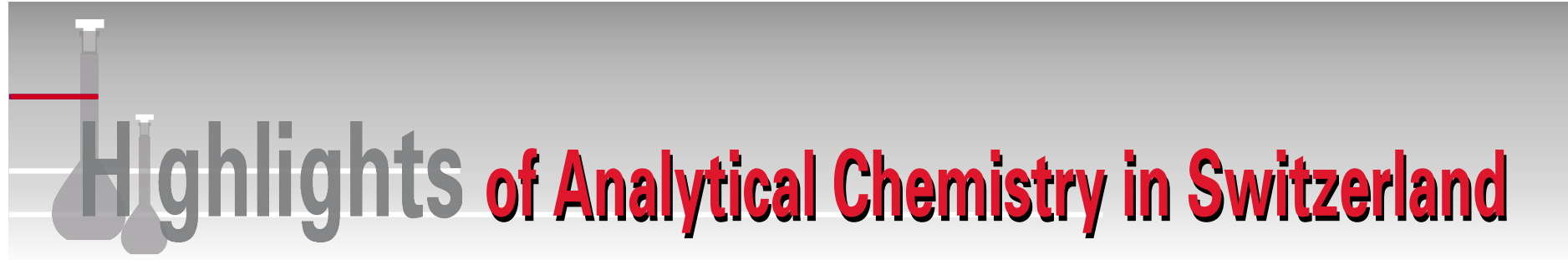

\section{Does Ski Tourism Affect Alpine Bird Fauna?}

\section{Susanne Jenni-Eiermann ${ }^{\star a}$ and Raphael Arlettaz ${ }^{\mathrm{ab}}$}

*Correspondence: Dr. S. Jenni-Eiermanna , Tel.: +414146297 00, Fax: +414146297 10, E-mail: susi.jenni@vogelwarte.ch

aSwiss Ornithological Institute, $\mathrm{CH}-6204$ Sempach; bZoological Institute, University of Bern, $\mathrm{CH}-3012$ Bern

Keywords: Capercaillie - Faecal corticosterone metabolites . Grouse $\cdot$ Human disturbance $\cdot$ Stress ecology .

Winter snow sports

Human-generated stress of wildlife, through continually developing outdoor recreational activities, is of increasing conservation concern as it often adds to other factors already adversely affecting the dynamics of vulnerable populations. It remains unclear, however, to what extent rapidly spreading free-riding snow sports, as a result of the intensifying winter tourism industry, actually elicit detrimental stress upon wildlife, with associated fitness and survival costs. Using a non-invasive method, we evaluated the levels of physiological stress induced by free-riding snow sports onto free-ranging black grouse and capercaillie, both declining species of alpine ecosystems. The concentration of stress hormone metabolites were measured in droppings collected in the snow.

In black grouse the effect of human encounter on the concentration of the faecal corticosterone metabolites (FCM) was investigated experimentally. During wintertime black grouse rest most of the time in igloos, which they burrow after each feeding session - twice a day - anew. Hence, faeces are deposited twice daily and every

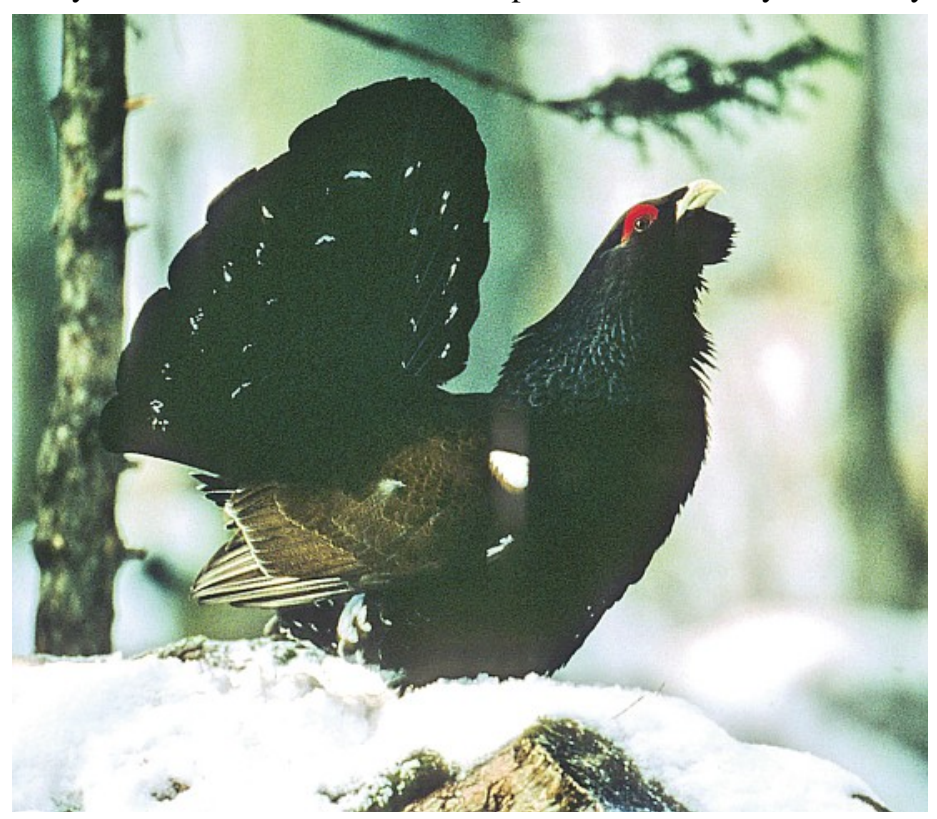

Male capercaillie (Photo: (c) Gilbert Hayoz) time in a new igloo. In an undisturbed habitat radiomonitored birds were actively flushed from their snow burrows once a day, during four consecutive days. The concentration of the faecal corticosterone metabolites (FCM), determined with enzyme immunoassay, increased continuously from control day throughout the end of the experiment. Since flushing of black grouse and faecal sample collection took place in the early afternoon, birds apparently remained in a stressed state up to a minimum of $16 \mathrm{~h}$ after a flushing event. In a comparative analysis, FCM of black grouse and capercaillies were analysed in droppings collected in habitats of various levels of human impact in the Alps as well as in the Black Forest. In both species the FCM concentration was significantly increased in birds living in areas with moderate to high recreation intensity compared to those with low recreation intensity.

The analysis of the metabolites of the stress hormone corticosterone in droppings proved to be a valuable method to monitor the effect of human recreation activities on the metabolism of freeranging grouse. The studies showed that repeated disturbances may clearly induce stress and, therefore, potential long-lasting physiological effects which affect the birds'fitness and survival.

Received: February 23, 2008

\section{References}

D. Thiel, S. Jenni-Eiermann, V. Braunisch, R. Palme, L. Jenni, J. Appl. Ecology, in press.

R. Arlettaz, P. Patthey, M. Baltic, T. Leu, M. Schaub, R. Palme, S. JenniEiermann, Proc. Royal Soc. London 2007, 274, 1219.

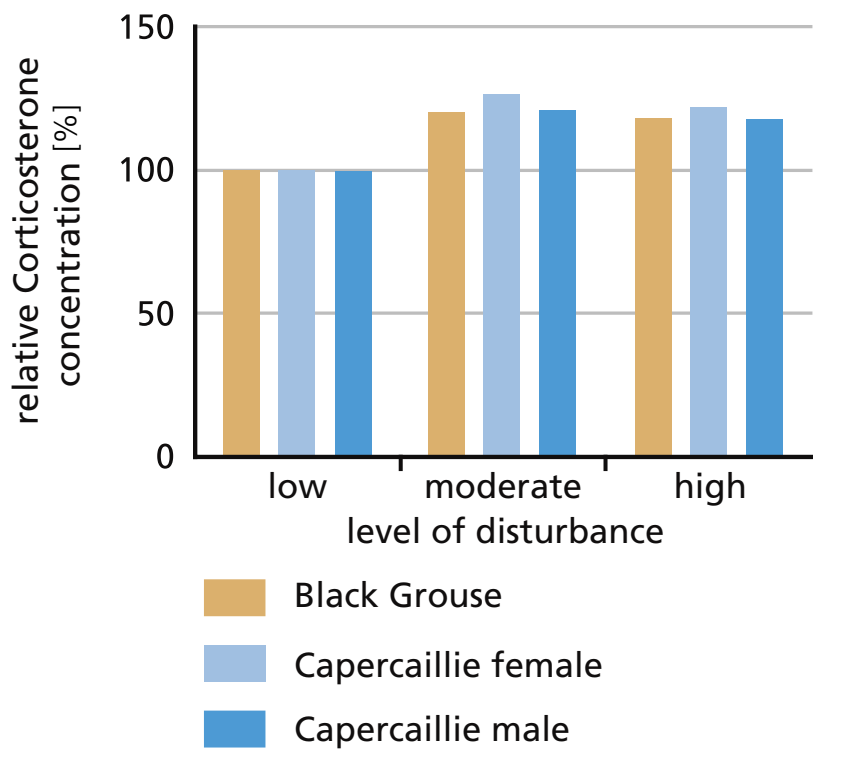

Faecal corticosterone metabolites of black grouse and capercaillie living in sites with various levels of disturbance by skiers and snowboarders. The level of 'low disturbance' was set at $100 \%$. 